\title{
Characterization by Scanning Electron Microscopy on Drill Boride and Drilling Performance of Tool Steels
}

Victor Olmos Domínguez ${ }^{1}$, Marco Doñu Ruiz ${ }^{2}$, Noe Lopez Perrusquia ${ }^{2}$ and Leopoldo Garcia Vanegas ${ }^{3}$

${ }^{1}$ Universidad Tecnológica de México, ESTADO DE MÉXICO, Distrito Federal, Mexico, ${ }^{2}$ Universidad Politécnica del Valle de México, Tultitlan, Distrito Federal, Mexico, ${ }^{3}$ Universidad Tecnológica Fidel Velazquez, ESTADO DE MÉXICO, Distrito Federal, Mexico

Nowaday the industry demands increasingly resistant materials that meet the needs of manufacturing processes, so they choose to improve tools with coatings to improve the life of the tool. For this investigation a monolayer of iron boride was formed using the thermochemical process of boron, by means of the technique of boring in powder pack with dehydrated paste of reuse; with the purpose of observing the effect of the drill with layer in drilling and to analyze the effect of the wear of the tool on an aluminum alloy, used in the section of aerospace and automotive industry.

A commercial twist drill with a diameter of 3/16 in, made of AISI M2 steel with vacuum nitriding by the manufacturer, was used. The drills were subjected to a thermochemical boronizing treatment using the pack boring technique with dehydrated reuse powder paste as a boriding medium [1], at a temperature of $1173 \mathrm{~K}$ and $6 \mathrm{~h}$ of exposure time in a conventional furnace without a controlled atmosphere. Phases on each conditions were identified by X-ray diffraction (XRD). The diffraction test was under taken by scanning from $20^{\circ}$ to $90^{\circ}$. Moreover, the drill was subjected to the drilling process in the manufacture of blind holes on an aluminum alloy 6061 T6 by the flood method, using a 3-axis CNC VMC-640 vertical machining center, under the following machining regime: cutting speed $60 \mathrm{~m} / \mathrm{min}$ and feed speed 0.0635 $\mathrm{mm} / \mathrm{r}$; 6400 holes were made, according to Taylor's equation is estimated at $256 \mathrm{~min}$ of machining. At the end of the drilling process, the characterization of the drill hole surface was performed by means of a JEOL JSM-IT100 scanning electron microscope and energy dispersive spectroscopy (SEM).

The thermochemical treatment was applied only to the tip of the hole where the main edges of the tool are located. Figure 1 shows the drilling process using a drill with a helical geometry with boron atom coating, Figure $1 \mathrm{~b}$ shows the geometry of the spiral drill consisting of a cutting point at the tip of a cylindrical shaft with spiral channels; these channels act as an Arquímides screw, which lifts the chip from the hole. Figure 1c shows XRD pattern of single layer obtained by the thermochemical treatment of boron (black line) with peaks of $\mathrm{Fe}_{2} \mathrm{~B}$, and the presence of nitrides type $\mathrm{Fe}_{2} \mathrm{~N}, \mathrm{Fe}_{3} \mathrm{~N}$ and $\mathrm{Fe}_{4} \mathrm{~N}$ (grey line) as the material was received.

Figure 2 shows the chisel edge of the drill hole with boron atoms after $72 \mathrm{~min}$ of machining. Figure $2 b$ shows the wear of the main edge and elemental analysis by EDS reveals the presence of an accumulated edge on the cutting tool. The effect is the presence of an aluminum mass adhesion of $67.1 \%$, which presented failures in the drilling process due to the formation of the built-up edge (BUE) [2]. According to Taylor's estimated lifetime, the drill hole in the boron condition has a $28.12 \%$ yield, in the case of the untreated hole, continues without failure. Figure $2 \mathrm{c}$ shows the wear on the chisel edge and the presence of a non-uniform raised edge on the cutting tool. These types of wear occur when the coating comes off, leaving the substrate exposed. 




Figure 1. The drilling process on $\mathrm{CNC}$ vertical machining center and the characteristics of the drill a) Drilling process in aluminum alloy 6061 T6 plate, b) It shows drill with helical geometry, and c) XRD pattern on drill as received and drill borided.

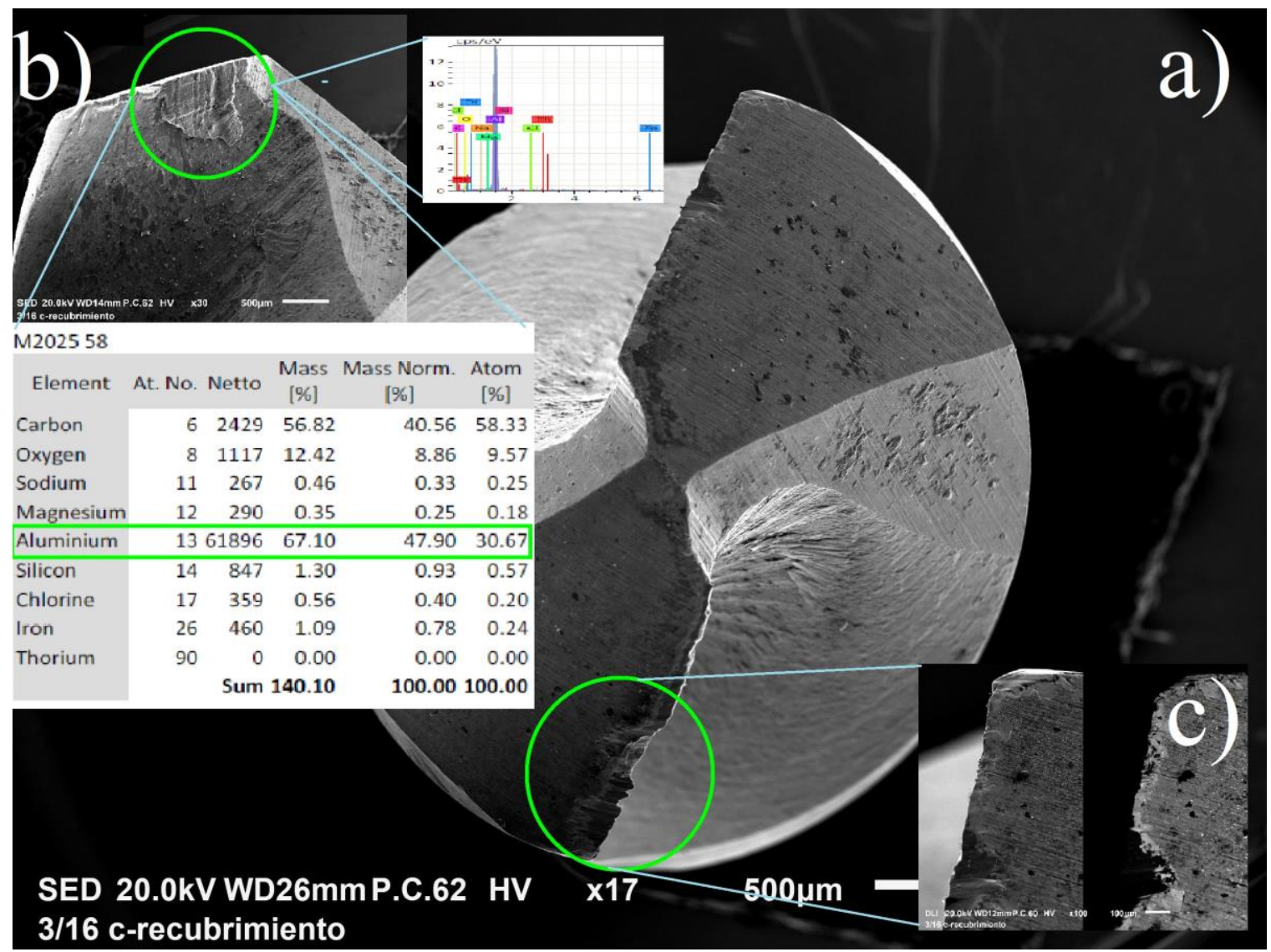


Figure 2. SEM image of drill borided after of machining a) Drill with boron atoms at the end of 72 minutes of machining, b) EDS on the main edge of the drill reveals the presence BUE of the aluminum alloy 6061 T6, c) Abrasion wear causes the drill to have a raised edge with boron atoms.

\section{References}

[1] M. A Doñu Ruiz, N. López Perrusquia, D. Sánchez Huerta, C.R. Torres San Miguel, G.M. Urriolagoitia Calderón, E.A. Cerillo Moreno, J.V. Cortes Suarez, Thin Solid Films, 596 (2015), p.147154.

[2] Zhaoju Zhu, Kai Guo, Jie Sun, Jianfeng Li, Yang Liu, Yihao Zheng, Lei Chen. Materials Processing Tech. 259 (2018), p. 270-281 